\title{
Application of Low-carbon Urban Theory in Urban Planning
}

\author{
Xi'an Urban Planning and Design Institute, Xi'an 710082
}

\section{Overview of low-carbon city theory}

\subsection{Meaning of low-carbon city}

Low-carbon city, according to the literal meaning of understanding is in the city planning, for urban planning to provide accurate direction, that is to say the city in the process of development to low-carbon economy as the main direction of development, led the city to form a low-carbon model, creating low-carbon city. In this low-carbon city planning, the transportation system as part of the entire plan, with its related economic industries and related urban space and so on.

\subsection{Characteristics of low-car- bon city}

Low-carbon city for energy conservation, green and innovative have put forward new requirements. Energy efficiency is mainly in the process of urban planning, we should pay attention to reduce waste emissions, emissions and reduce energy waste. Green environmental protection is mainly in the city to carry out reasonable planning, we should try to reduce the damage caused by the environment and pollution, people and the ecological environment can be harmonious to get along. Innovation is mainly reflected in the planning and development of the city, adhere to the low-carbon economy as the most important direction, while protecting the ecological environment and economic development, so that all industries in the city have to carry out a certain degree of innovation, low development Carbon economy and green economy related in- dustries.

\section{The Application of Low-carbon Urban Theory in Urban Planning}

2.1 Actively planning to build low-carbon industrial system, and promote the integration of industry and low-carbon city development

The development of urban and rural areas in line with the characteristics of low-carbon strategic planning from the industry layout. First, through planning means to accelerate backward production and industry restructuring and reduce energy consumption. Combined with urban resources, environmental capacity and carbon emissions planning targets, increase pollution technology, equipment and business exit efforts, and optimize the advantages of traditional industrial layout, effectively improve the efficiency of energy use, reduce production links in the water, solid waste and other pollution emissions. Combined with urban and rural areas of the carrying capacity of the environment, the amount of resources, industrial function layout, transportation conditions. Second, we must vigorously develop low-carbon emerging industries to combine the overall planning of urban and rural development. In order of increase new technologies, new industries, green energy, clean technology and new energy vehicles and other energy-saving environmental protection industry's comprehensive investment efforts to promote its large-scale development. Third, we must accelerate the development of low-carbon services,
Abstract: At present, the pace of construction and development in China is getting faster and faster. The development of industrialization has also promoted the social productive forces of our country and the economic level of our country. In addition, the industrialization has greatly promoted the development of our country. The development of urban and rural integration. The area of the city is growing, and the number of people living in the city is growing, and there is a growing trend.

Key words: Low-carbon city; urban planning

Published online: 15th July, 2017

to encourage accommodation, catering and wholesale and retail trade and other business innovation business model, and actively develop e-commerce and other low-carbon model. Fourth, strengthen the planning and guidance of urban construction projects to guide and guide the "building waste" and "chaos to change the land use", and effectively strengthen the scientific nature of the construction industry planning, give full play to planning in the construction of land control and guidance.

\subsection{Follow the design principles and content}

2.2.1 Principles of eco-city plan- 
ning and design: 1) Adhere to the ecological priority, environment-based. In the ecological city planning and design, the natural basis of this project should be fully played out, in the allowable range as much as possible to maintain the original natural environment is not damaged, so that it can be protected and continued; 2) Optimize the industrial structure, build a low carbon industry chain. Urban planning to do the city construction technology and market development effectively combined, and strive to achieve the industry from energy consumption to science and technology as the point, to build a pillar industry with scientific and technological direction; To do to focus on projects to drive those low energy consumption, green industry development.

\subsubsection{Eco-city planning and design} content:

Eco-city planning and design is the premise of the whole eco-city construction, in the building energy efficiency, the full use of external wall energy-saving technologies, doors and windows energy-saving technologies, lighting energy-saving technologies, make full use of solar energy; In the natural environment planning and design, make every effort to ensure that the previous urban ecology, planning and design to modern architecture and ecological environment of the integration of planning and design concepts, as much as possible to ensure that the city's lakes, rivers, ponds, which according to the water system to do the construction of artificial river, the city's water supply and drainage systems and these natural water system linked; In the traffic planning and design materials, in the building energy-saving, comprehensive use of external wall energy-saving technologies, energy-saving windows and doors, energy-saving lighting technology, make full use of solar energy; In the natural environment, planning and design, do their utmost to ensure that past urban ecology, planning and design with modern architecture and ecological integration of planning and design concepts, as much as possible to ensure that in the past the city's lakes, rivers, ponds, etc., and according to these water systems do the construction of artificial river, the city's water supply and drainage system and these natural water system linked.

\subsection{Optimize the planning process}

\subsubsection{Planning stage}

Before planning and design, you need to plan the project and provide support for planning and design. The specific work includes: 1) To investigate the information about the project area, including carbon resources, carbon emissions and carbon sinks, to analyze its impact on urban economy, material, environment and social factors. 2) According to the information collected, the project should be optimized and analyzed, and the advantages and difficulties of the project should be clarified, the low carbon target and the main direction should be formulated, and detailed information should be provided for the follow-up design to ensure the scientificity and feasibility of the planning and design.

\subsubsection{Design phase}

After the planning is completed, you can start the urban planning and design, at this stage, the most important job is to accurately assess carbon emissions and rationalize the design of low-carbon prospects, comparing the economic and scientific to choose the optimal plan. At this stage, carbon emissions assessment plays a key role, which includes assessment of design and government-related policies, will have a certain impact on the total amount of carbon emissions, the maximum degree of assurance for the accuracy of the assessment should be selective, predictive functional characteristics.

All in all, at this stage, China's economic level has increased rapidly.
At the same time, economic growth has also promoted the construction and development of China's urbanization. The planning of urban construction is closely related to the economic level of our society. The construction of the city is relatively developed with the growth of the economy. In addition, the development of the city also has inconsistent and unbalanced characteristics. Urban planning is very important to the construction of the city, people in the growing awareness of environmental protection today, to achieve its low-carbon planning and design is particularly important, it is necessary to get our attention.

\section{References:}

[1] Xu Ying. Low-Carbon City Theory in Urban Planning Application $[\mathrm{J}]$. Science and Technology Outlook, 2015, 02: 236.

[2] Li Fangzheng, Xiao Yao, Li Xiong. Application of Low-Carbon City Concept in Greenway Planning - Taking Qian'an City as an Example [J]. Chinese Journal of Landscape Architecture, 2015,09: 55-59.

[3] Zhu Cuiping. Low-Carbon Urban Planning Index System Construction and Case Analysis [D]. Zhejiang University, 2013.

[4] Li Xiaojun, Yu Lu. Application of light environment analysis in urban low-carbon ecological planning - Taking Shantou in Guangdong as an example [A]. China Urban Planning Society, Guiyang Municipal People's Government. New normal: inheritance and change - China Urban Planning Society, Guiyang Municipal People's Government: 2015: 12. China Urban Planning Society, Guiyang Municipal People's Government: 2015:12.

[5] Cai Ke, Zang Heng. Application of Urban Growth and Optimal Scale Theory in Urban Development Planning [J]. Project Construction and Design, 2012, 11: 87-90. 